\title{
ARTIGOS
}

\section{SUSTENTABILIDADE E JOALHERIA: RECICLAGEM DE EPS PARA APLICAÇÃO EM JOIAS}

\author{
SUSTAINABILITY AND JEWELRY: EPS RECYCLING FOR JEWELRY APPLICATION
}

\section{SUELLEN DO NASCIMENTO DE SOUZA MORENO | UFSM \\ MARIANA KUHL CIDADE, Dra. |UFSM}

\begin{abstract}
RESUMO
Com o grande aumento da geração de resíduos sólidos urbanos, um dos principais modos de favorecimento de práticas sustentáveis encontra-se a divulgação e disponibilização de meios adequados para sua separação, coleta e triagem. Além disso, mesmo que coletados e triados, determinados resíduos permanecem com pouco interesse comercial, o que os leva a uma diminuição no seu potencial de reciclagem. Este trabalho apresenta um levantamento dos meios de descarte e coleta de resíduos secos em Santa Maria (RS), voltando para o reaproveitamento de resíduos de poliestireno expandido (EPS). Foi investigada a importância do descarte correto de materiais, além de como um material sem interesse comercial pode ser valorizado através de sua aplicação na joalheria. Foi desenvolvida uma coleção de joias composta por anel, bracelete e um par de brincos, visando o uso de EPS como elemento decorativo. O levantamento mostrou que há uma carência de informações para a população acerca do tipo de separação a ser realizada nos resíduos domésticos, bem como um número expressivamente menor de contêineres destinados a resíduos recicláveis. Por fim, para demonstração da fabricação, o anel foi executado em prata, por meio do processo de fundição por cera perdida, com a aplicação do EPS reciclado.
\end{abstract}

PALAVRAS CHAVE: Sustentabilidade; reciclagem; materiais descartados; joias.

\begin{abstract}
With large increase in the generation of urban solid waste, one of the main methods of supporting sustainable practices is the dissemination and availability of adequate means for their separation, collection and sorting. Moreover, even if collected and sorted, certain wastes remain of little commercial interest, which leads to a decrease in their recycling potential. This paper presents a survey of the means of disposal and collection of dry waste in the city of Santa Maria (RS), aiming at the reuse of expanded polystyrene (EPS) waste. The importance of proper disposal of materials was investigated, as well as how a material without commercial interest can be valued through its application in jewelry. A jewelry collection consisting of a ring, bracelet and a pair of earrings was developed with the use EPS as a decorative element. The survey showed that there is a lack of information for the population about the household waste separation, as well as a significantly lower number of containers for recyclable waste. Finally, for manufacture demonstration, the ring was produced in silver, through the lost wax casting process, with the application of recycled EPS.
\end{abstract}

KEY WORDS: Sustainability; recycling; discarded materials; jewelry. 


\section{INTRODUÇÃO}

O aumento da aquisição de bens de consumo pela população no Brasil, junto com seu modo de produção e comercialização nesses últimos anos, tem gerado um acúmulo de lixo, o que consequentemente leva à degradação ambiental (CARVALHO; XAVIER, 2014; BARELLI, 2009). Os componentes do lixo doméstico no Brasil são chamados de resíduos sólidos urbanos (RSU). Segundo o SEBRAE (2017) e a Política Nacional de Resíduos Sólidos (PNRS), Lei 12.305/2010 (BRASIL, 2010), entende-se por resíduos sólidos as partes que sobram de processos derivados das atividades humanas e animal e de processos produtivos, tais como a matéria orgânica, o lixo doméstico, os efluentes industriais e os gases liberados, cuja destinação final se procede, se propõe proceder ou se está obrigado a proceder. Conforme Junior (2006) foi a partir da metade do século XXI que o gerenciamento dos RSU começou a chamar atenção da população, tanto pelo acúmulo quanto pelo descarte incorreto dos mesmos. O autor comenta também que a forma como estes resíduos são manipulados, tratados e destinados podem mudar suas características iniciais, causando perigo à saúde pública e ao meio ambiente (JUNIOR, 2006).

No início do século XXI a população mundial foi estimada em 6,2 bilhões de habitantes, que geravam a cada ano mais de um bilhão de toneladas de resíduos sólidos, sendo a parte brasileira cerca de 83 milhões de toneladas (MANCINI; ZANIN, 2004). Os autores ainda afirmam que de todo este volume de resíduos, para boa parte não eram apresentados um tratamento e uma disposição adequada (MANCINI; ZANIN, 2004). Na Europa, algumas estratégias vêm sendo executadas para melhorar a qualidade de vida dos cidadãos e do meio ambiente. Uma destas é a reciclagem, que segundo a PNRS (BRASIL, 2010) é um processo de transformação dos resíduos coletados que envolve a alteração de suas propriedades. A European Commission (PLASTICS EUROPE, 2013) defende que os objetivos e metas estabelecidos na Legislação Europeia têm sido os principais motores para melhorar a gestão de resíduos, estimulando a inovação na reciclagem, reduzindo o uso da disposição em aterros sanitários e criando incentivos para a mudança de comportamento dos cidadãos.

Em uma tentativa de lidar com a poluição de polímeros, a Comissão Europeia apresentou uma estratégia com o objetivo de garantir que até 2030 cada peça de embalagem polimérica possa ser reutilizada ou reciclada (PARLAMENTO EUROPEU, 2018). A maior parte dos países europeus vem seguindo regras bastante rígidas com relação aos RSU (JURAS, 2012). Juras (2012) fala ainda que a Alemanha é pioneira em adotar medidas destinadas a avaliar as questões dos RSU; já a Bélgica tem o melhor sistema de reciclagem de lixo da Europa, pois quase três quartos dos resíduos domésticos produzidos são reutilizados, reciclados ou compostos (PENNA, 2017). Na Inglaterra, desde 1996, taxas de lixo como política nacional são aplicadas, pelas quais os cidadãos pagam multas para resíduos não separados corretamente, onde o valor depende do volume produzido (SCHERER; VIEIRA, 2015). Já na região ao norte da Bélgica, em Flandres, a geração per capita de lixo tem se mantido estável desde 2000, e uma das principais estratégias dessa região para reduzir o desperdício e geração de lixo está na raiz do problema: o projeto dos produtos (PENNA, 2017).

De acordo com a Pesquisa Nacional do Saneamento Básico (PNSB) de 2008, do Instituto Brasileiro de Geografia e Estatística (IBGE), os RSU geralmente são destinados a aterros sanitários e lixões. Entretanto, em algumas cidades brasileiras, sistemas de coleta seletiva foram implementados, os quais abrangem a coleta domiciliar dos RSU, onde estes são separados pela comunidade doméstica e empresarial entre lixo seco e úmido. De acordo com Instituição de Pesquisa Econômica Aplicada (IPEA, 2012), para diminuir a quantidade de resíduos dispostos nos aterros sanitários e nos lixões, é necessária a criação de sistemas de coleta seletiva.

A coleta seletiva de resíduos sólidos é previamente segregada conforme sua constituição ou composição e destinada a Centros e/ou Associações de Triagem (BRASIL, 2010). Estes são fundamentais no reprocessamento de RSU, pois colaboram para a separação dos resíduos e geram renda para famílias associadas (PALOMBINI, 2015; PALOMBINI, CIDADE e JACQUES DE JACQUES, 2016). A exemplo, na cidade de Porto Alegre, capital do Rio Grande do Sul, todos os RSU úmidos (orgânicos) são despejados pela população em contêineres espalhados pela cidade e transportados diretamente para aterros, enquanto os resíduos secos são recolhidos pelo sistema de coleta seletiva em dias específicos, sendo posteriormente destinados a Associações de Triagem pra serem separados para fins de venda; isto é, os resíduos pós-classificados são vendidos a empresas que reciclam e utilizam como material secundário (PALOMBINI, CIDADE e JACQUES DE JACQUES, 2016). Entretanto, muitas vezes, por falta de conscientização por parte da comunidade, o lixo contido no interior dos containers espalhados pela cidade acaba sendo misturado em úmido e seco.

Um dos materiais de maior recepção nestas Associações de Triagem são os polímeros. Entretanto, as embalagens poliméricas são consideradas uma preocupação global devido ao seu grande volume empregado nos últimos anos. Os polímeros, são materiais que vêm sendo utilizados há milhares de anos e, muitas vezes, acabam substituindo diversos materiais, tais como o aço, o vidro e a madeira, devido às suas características como o baixo peso e 
custo, elevada resistência mecânica, química e facilidade de aditivação (ASHBY; JOHNSON, 2011). Contudo, um polímero com menos interesse econômico de reciclagem, em Associações de Triagem, é o Poliestireno Expandido (EPS).

O poliestireno (PS) foi inventado em 1930, segundo Peltier e Saporta (2009), sendo um homopolímero resultante da polimerização do monômero de estireno. Trata-se de uma resina do grupo dos termoplásticos, onde sua característica reside na fácil flexibilidade ou moldabilidade sob a ação do calor, o que a deixa em forma líquida ou pastosa (ASHBY; JOHSON, 2011). Segundo Ashby e Johson (2011) e Lima (2006), o PS é dividido em quatro tipos básicos: o cristal (homopolímero amorfo, duro, com brilho e elevado índice de refração, utilizado em artigos de baixo custo, como copos); resistente ao calor (para confecção de peças de máquinas ou automóveis, gabinetes de rádios e TV, grades de ar condicionado, peças internas e externas de eletrodomésticos e aparelhos eletrônicos, ventiladores e exaustores); de alto impacto (contém de 5 a 10\% de elastômero, utilizado na fabricação de utensílios domésticos e brinquedos); e o PS expandido, sendo uma inclusão em sua composição de aditivos de expansão, que o torna uma espuma, sendo aplicado em bandejas para embalagem de alimentos, protetor de equipamentos, isolantes térmicos, pranchas para flutuação, geladeiras isotérmicas, entre outros.

O PS é um material bastante utilizado nos produtos, mas acabam sendo desvalorizados na hora de sua reciclagem, por ter menos interesse econômico. Considerado uma comodity, seu valor como resina virgem é barato (ASHBY; JOHSON, 2011), mas ao incluir aditivos de expansão em sua composição, tornando-o uma espuma (EPS), e sendo conhecido popularmente como Isopor ${ }^{\circledR}$, sua densidade baixa consideravelmente (ASHBY; JOHSON, 2011). Isto significa que uma mesma quantidade de resina passa a ocupar um volume muito maior, levando, entre outros fatores, a um também relativo maior custo em seu transporte e menor interesse comercial em sua aquisição. Conforme Lefteri (2014), o EPS contém $98 \%$ de ar e $2 \%$ de polímero virgem, o que encarece o seu transporte e consequentemente dificulta a sua reciclagem. O Plastivida (2018) afirma, que o Brasil, em 2012, reciclou cerca de $34,5 \%$ do EPS que consumiu, ou seja, reciclou 13.570 das 39.340 toneladas de pós consumo.

De acordo com Cadore (2015) o consumo é necessário e tem um papel importante dentro da sociedade para que possa entender as organizações sociais. Porém, a ótica consumista, racionalizada para a aquisição, e o descarte cada vez mais acelerado, faz com que a população não analise a trajetória dos produtos utilizados, desde sua produção até chegar em suas mãos (PEREIRA; HORN, 2009). As atividades humanas ultrapassam os limites e diminuem a qualidade do mundo, além de ameaçar o bem-estar de gerações futuras (ASHBY; JOHSIN, 2011). As empresas são os grandes atores dentro desse sistema de produção de consumo, e seu papel é fundamental para a mudança em direção a sustentabilidade, pois possuem os maiores recursos de conhecimento, organização e capacidade de tomar iniciativas (VEZZOLI; MANZINI, 2008). Pode-se entender como uma solução sustentável aquela que possui um valor duradouro em termos de significado e características (WALKER, 2006). A área do design oferece soluções a problemas, ao projetar novos artefatos, ou até mesmo modificar os já existentes, e esta precisa apresentar opções que incluem a sustentabilidade (CADORE, 2015; MANZINI, 2008). O designer, ao projetar objetos, estuda o comportamento e os significados das ações que possuem entre o objeto e o sujeito (CADORE, 2015). Portanto, para a reciclagem e reuso de materiais é necessário, por parte do consumidor, um posicionamento consciente, como também por parte dos fabricantes. Sendo assim, a utilização de materiais recicláveis surge como uma nova solução para o mundo do design e da joalheria contemporânea. Esta por sua vez, sempre esteve presente na vida do homem, desde os tempos mais remotos, através de seus costumes, tradições, crenças e evoluções, assumindo diversas funções em diferentes épocas e culturas.

Com isto, o presente artigo consiste no desenvolvimento de uma coleção de joias sustentáveis com a aplicação de um material com pouco interesse econômico de reciclagem, o Poliestireno Expandido (EPS). Para isto, foi realizada uma averiguação sobe o descarte de resíduos sólidos urbanos da cidade de Santa Maria/RS e quais os problemas enfrentados em relação ao descarte, coleta e materiais.

\section{SUSTENTABILIDADE: DESCARTE DE RESÍDUOS}

A geração de resíduos sólidos urbanos (RSU) no Brasil foi de 78,4 milhões de toneladas em 2017, aumento de cerca de $1 \%$ em relação a 2016 , onde 6,9 milhões de toneladas não foram coletadas pelos serviços municipais e tiveram destino desconhecido, conforme o Panorama dos Resíduos Sólidos (ABRELPE, 2017). Destes resíduos, 40,9\% do que é capturado pelo sistema de coleta regular é descartado de forma inadequada, num total de 29 milhões de toneladas (ABRELPE, 2017). Este alto volume é enviado a lixões ou a aterros (ABRELPE, 2017). O dado mais alarmante do Panorama foi o aumento da destinação inadequada no país: houve crescimento de uso de lixões de 3\% no ano de 2016 para 2017, passando de 1.559 a 1.610 o número de cidades que fazem uso desse expediente para destinação final (ABRELPE, 2017). Já na região Sul do país, 1.191 municípios geraram neste mesmo ano uma quantidade de 22.429 toneladas/dia de RSU, sendo que $89 \%$ foram 
enviados a aterros sanitários e 11\% a lixões (ABRELPE, 2017).

O gerenciamento de RSU é um conjunto de ações exercidas de forma direta ou indireta, nas etapas de coleta, transporte, transbordo, tratamento, destinação e disposição final ambientalmente adequada dos rejeitos (BRASIL, 2010). Já a gestão integrada de RSU é um conjunto de ações voltadas para achar soluções para os resíduos, considerando as dimensões políticas, econômicas, ambientais, culturais e sociais, com controle social e sob premissa de desenvolvimento sustentável (BRASIL, 2010). Na gestão e gerenciamento de RSU pode ser observada a seguinte ordem de prioridade (Figura 01): não geração, por meio do consumo consciente, redução, reutilização, reciclagem, tratamento dos resíduos e disposição final ambientalmente adequada dos rejeitos (BRASIL, 2010).

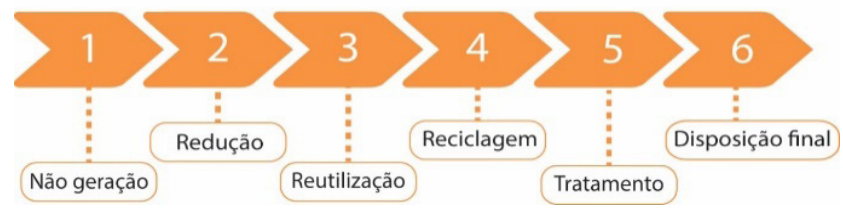

Figura 01 - Ordem de prioridade no gerenciamento de RSU Fonte: Adaptado de Brasil (2010).

A redução é compreendida como projetar produtos de modo a minimizar o uso de materiais e energia nas etapas de fabricação (AZAPAGIC; EMSLEY; HAMERTON, 2003). Pode-se chamar de "reutilização" o método de aproveitamento dos resíduos sem sua modificação biológica, física ou físico-química (BRASIL, 2010), onde os materiais são reaproveitados, do modo como são, sem a utilização de qualquer processo que modifique sua estrutura "internamente". A reciclagem é entendida como um processo de transformação dos resíduos sólidos urbanos que engloba a alteração de suas propriedades físicas, físico-químicas ou biológicas, com vistas à transformação de insumos ou novos produtos (BRASIL, 2010). A opção mais desejável nessa hierarquia (gestão) é a redução do uso de recursos, pois leva à redução na geração de resíduos (AZAPAGIC; EMSLEY; HAMERTON, 2003). A disposição final adequada dos RSU de acordo com a PNRS (BRASIL, 2010), inclui a reutilização, a reciclagem, a compostagem, a recuperação e o aproveitamento energético ou outras destinações permitidas pelos órgãos competentes.

Na cidade de Santa Maria, na região central do estado do Rio Grande do Sul, desde 2008, os RSU eram direcionados a um aterro sanitário com área de 27 hectares (MATGE, 2018c). A partir de 2012 o gerenciamento passou a ser do centro de tratamento de resíduo sólido, empresa privada da CRVR (Companhia Riograndense de Valorização de Resíduos), que opera fazendo a triagem de algumas cargas (MATGE, 2018c).
Segundo a CRVR, a central é composta por unidades de triagem, compostagem, tratamento de efluentes, além de aterro sanitário e infraestrutura administrativa (MATGE, 2018a). Matge (2018b) relata que de acordo com a Prefeitura Municipal de Santa Maria (PMSM), por mês, são descartadas 5.8 mil toneladas de lixo na cidade, sendo que esse cenário fica mais agravado pelo descarte inapropriado destes materiais. No ano de 2018, de acordo com uma pesquisa feita pela Secretaria de Meio Ambiente de Santa Maria, a cidade contava com 121 locais de descarte incorreto, como locais próximos a rios e áreas verdes, piorando a situação da cidade (MATGE, 2018b).

Como o intuito do artigo é a utilização do processo de reciclagem em um material de pouco interesse econômico, como o Poliestireno Expandido (EPS), foi necessária uma averiguação do comportamento do descarte de RSU na cidade de Santa Maria para a obtenção de possíveis informações sobre como é a logística deste resíduo. Para isso, foi executada uma pesquisa de campo visual feita na região central da cidade referente à destinação e coleta dos RSU, uma entrevista com a Prefeitura e, em seguida foi descrita a visitação de duas Associações de Reciclagem.

Segundo relatado pela Prefeitura da cidade, existem no total 610 unidades de contêineres alocados nas ruas e avenidas para a destinação e posterior coleta dos RSU (Figura 02). Destes, 600 unidades são para resíduos domésticos (contêineres de tonalidade cinza) e 10 contêineres na cor laranja para resíduos recicláveis, exemplificados na Figura 02 A. Conforme informado pela Prefeitura e por estar visível através de um adesivo informativo, no contêiner laranja são descartados os resíduos secos, como vidros, papéis, polímeros e metais (Figura 02 B). Já o de cor cinza, é destinado para outros tipos de materiais, onde no contêiner não consta nenhuma informação ou instrução de qual material deverá ser descartado pela comunidade. Também, não existe por parte da Prefeitura uma conscientização junto a população sobre a separação de lixo seco e molhado.

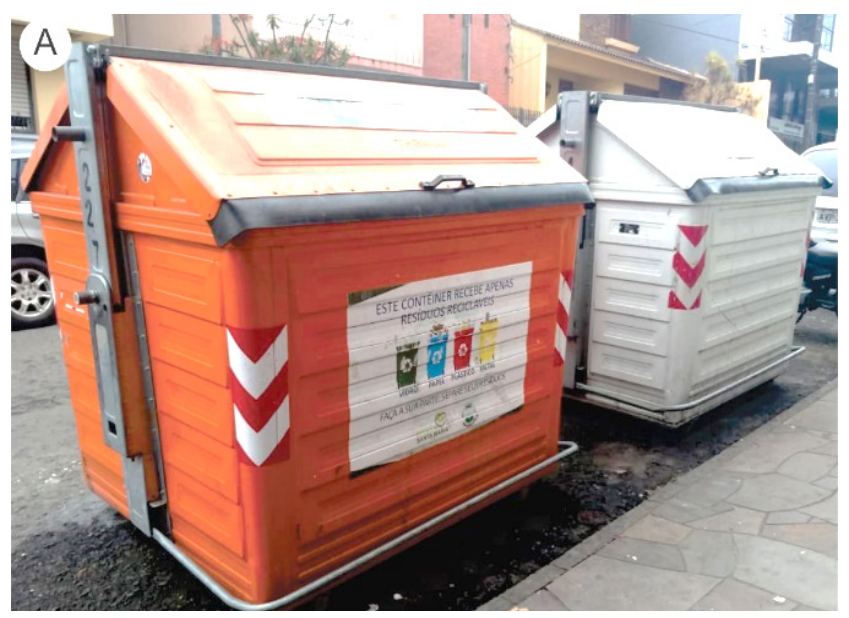




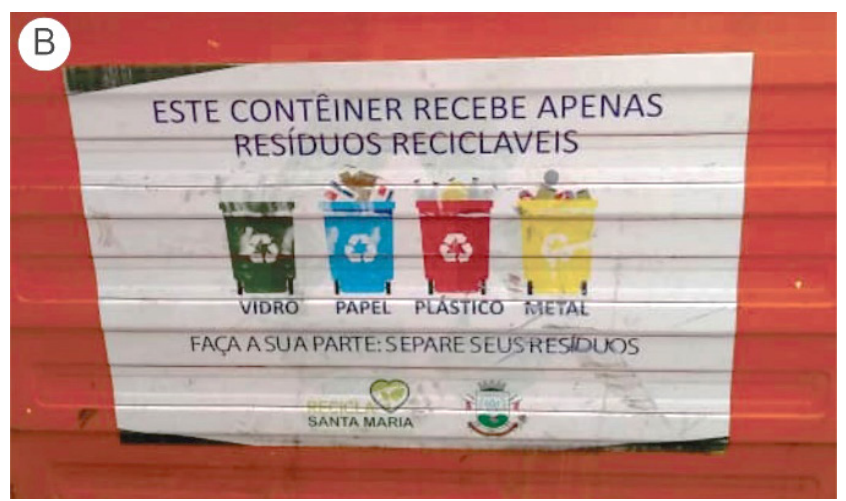

Figura 02 - Contêineres alocados na cidade: (A) exemplo dos contêineres laranja e cinza e (B) visualização das informações contidas no contêiner laranja

Fonte: Autoras.
Após a verificação de quais são os tipos de contêineres que existiam na cidade, foi efetuado um mapeamento de quantas unidades havia em uma determinada área, observando suas distribuições, quantidade, distâncias e cores. Para isso foi estipulada a região central, analisando mais dois bairros vizinhos, Nossa Senhora de Fátima e Bonfim. Na Figura 03, percebe-se que os contêineres são mal distribuídos, existindo quadras com apenas uma unidade ou outras com duas, ou até quadras com a inexistência de contêineres, dificultando o acesso das pessoas.

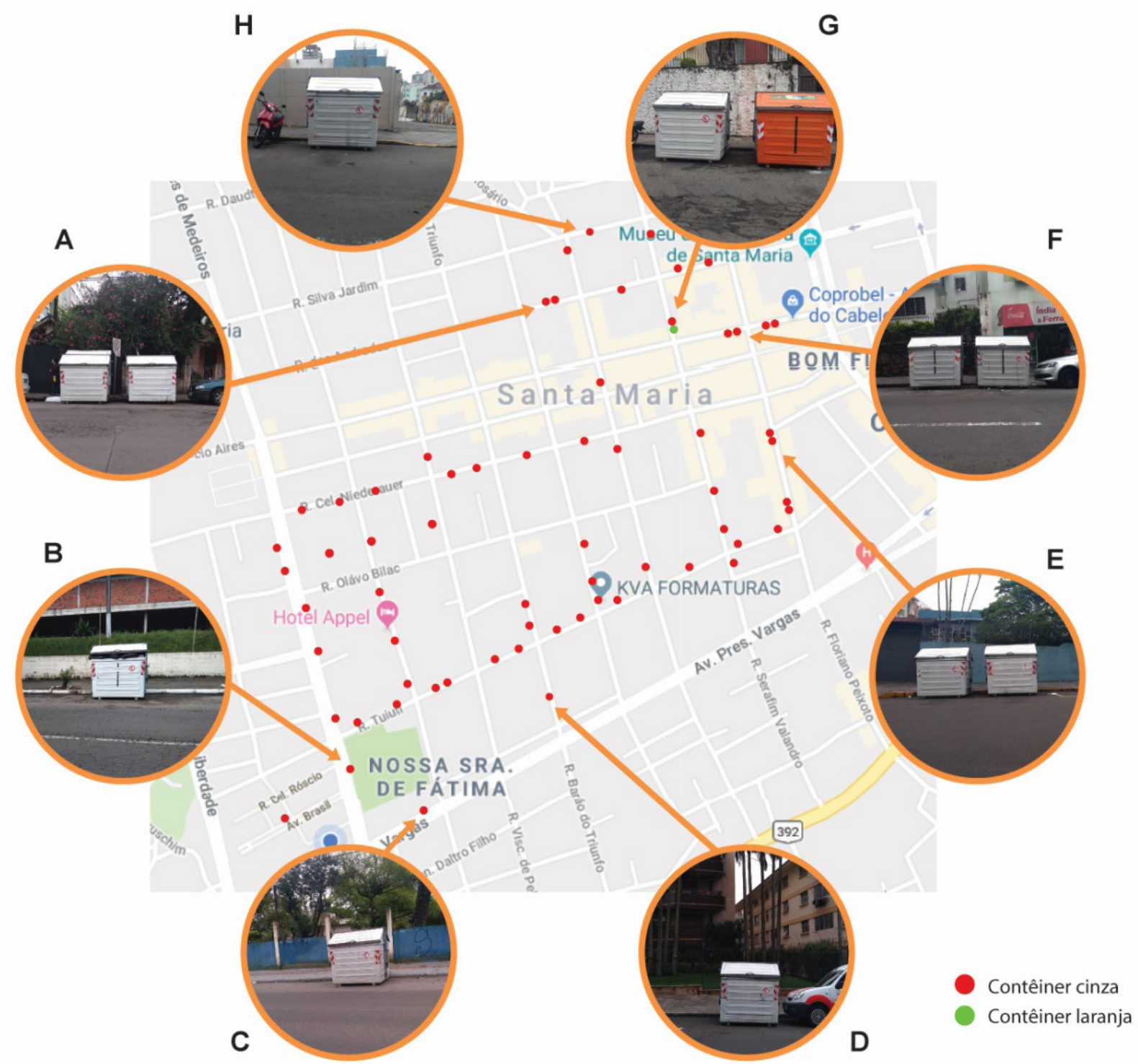

Figura 03 - Mapeamento, localização e distribuição dos contêineres na cidade de Santa Maria: (A) Rua dos Andradas, (B) Av. Borges de Medeiros, (C) Av. Presidente Vargas, (D) Barão do Triunfo, (E) Floriano Peixoto, (F) Venâncio Aires, (G) Serafim Valandro e (H) Silva Jardim Fonte: Autoras. 
Segundo a PMSM (2018a), os contêineres são distribuídos por região, respeitando uma distância de 100 metros entre eles. A quantidade de contêineres ainda depende da necessidade de cada região, sendo possível a colocação de dois contêineres dependendo da demanda. Notou-se que na região central foi encontrado apenas um contêiner na cor laranja (lixo reciclável) e nenhum na cor cinza.

A coleta de resíduos na cidade é classificada em coleta domiciliar convencional e conteinerizada (PMSM, 2018a). A coleta domiciliar convencional compreende a função das atividades de coleta manual porta a porta e transporte até a destinação final, utilizando caminhões coletores compactadores, sendo que a empresa prestadora de serviço atualmente é a Sustentare S.A (PMSM, 2018a). Já a coleta domiciliar conteinerizada compreende o recoIhimento de RSU utilizando contêineres e equipamentos de coleta com dispositivos hidráulicos. Estes dispositivos efetuam a elevação dos contêineres e o basculamento dos resíduos contidos nos mesmos para o interior do compartimento de carga instalados em veículos coletores. Através de prensa hidráulica, os resíduos sólidos são compactados no interior do compartimento de carga de forma a reduzir o volume, e após o esgotamento da capacidade de carga, o veículo coletor desloca-se para o local de descarga, para CRVR (Companhia Riograndense de Valorização de Resíduos). Entretanto, cabe salientar que como o contêiner de cor cinza não é identificado com informações do que se deve descartar em seu interior, muitas vezes o lixo seco e úmido acabam se misturando.

Hoje, além das coletas domiciliares e conteinerizadas existem três Associações de Reciclagem registradas pela prefeitura. Estas Associações fazem a separação dos RSU com possíveis interesses comerciais, onde todo o resíduo separado é vendido e, consequentemente, gera renda para os trabalhadores. Para este artigo, foram visitadas duas Associações (Figura 04). A primeira, a ASMAR (Associação dos Selecionadores de Materiais Recicláveis), tem aproximadamente 22 anos de funcionamento (Figura 04 A, B e C). Nela trabalham 21 pessoas, de ambos os sexos, sendo que todas utilizam luvas para manusear os materiais. Os resíduos chegam ao local misturados através da coleta domiciliar conteinerizada, tanto seco como o úmido, por um caminhão, e lá é feita toda a separação. Cabe ressaltar, que os resíduos que chegam a estas Associações deveriam ser os dos contêineres de cor laranja, por ser identificado para a população, mas muitas vezes isto não acontece, ocasionando a mistura do lixo. A separação acontece em uma esteira e depois deste processo o material vai para um setor de estoque, onde os com interesse comercial são enfardados para posterior venda. Os materiais que mais chegam nesta Associação, são papeis e polímeros, de diferentes dimensões e classificações, e os metais são os materiais em menos abundância. Os materiais descartados, por não terem interesse econômico, ficam dentro de um mesmo saco onde, posteriormente, uma empresa especializada recolhe-os e destina-os a aterros sanitários. Outro local visitado foi a ARSELE (Associação de Reciclagem Seletiva de Lixo Esperança). Seu funcionamento dá-se desde 2000, em um ambiente com uma estrutura precária, no qual trabalham cerca de 12 pessoas, de ambos os sexos. Os materiais também chegam misturados e na mesma quantidade que na ASMAR (Figura $04 \mathrm{D}$ e E), sendo provenientes das ruas, empresas, escolas e instituições. Após a separação, os materiais são estocados e vendidos conforme a procura. Ambas as Associações visitadas recebem vários tipos de polímeros, e entre eles o EPS. Este por sua vez, são selecionados e descartados, permanecendo sem interesse comercial e, consequentemente, destinados a aterros.
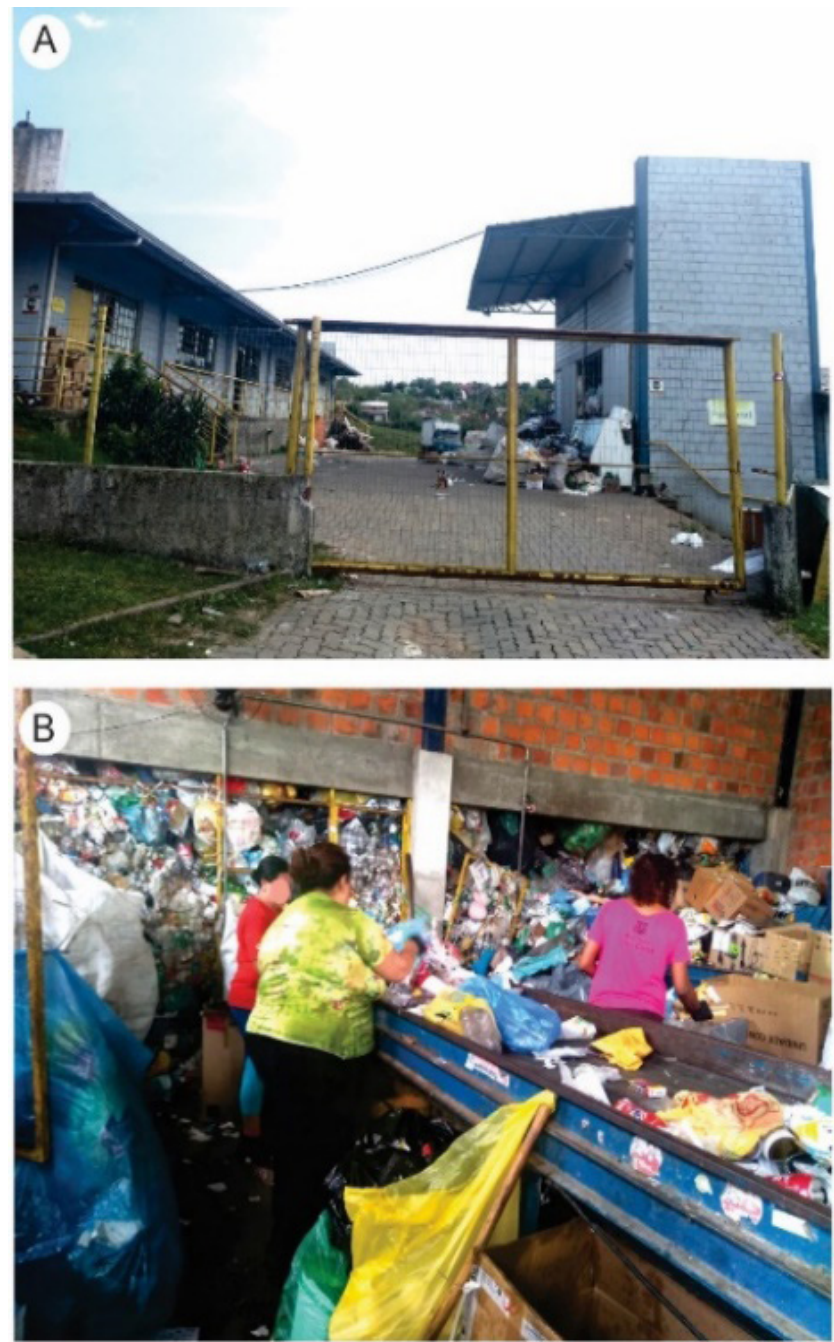

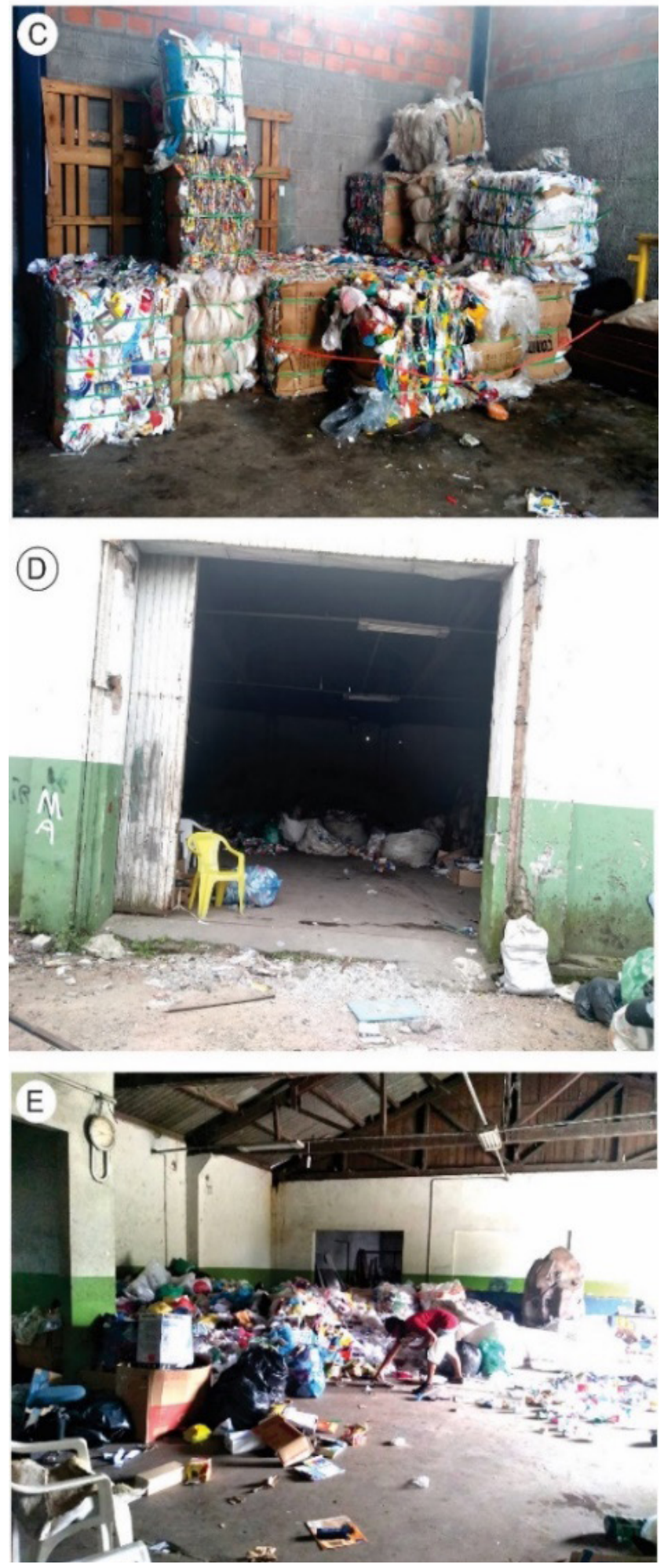

Figura 04- Associações visitadas: (A) entrada da ASMAR (B) separação dos materiais descartados, (C) materiais compactados, (D) ARSELE e (E) rejeitos

Fonte: Autoria própria, 2018.

\section{DESENVOLVIMENTO}

Com as análises feitas do descarte de RSU na cidade de Santa Maria e as visitações nas Associações, prossegue-se para o desenvolvimento das joias com o EPS. As joias no mercado atual são bastante diversificadas em termos de materiais, ocasionando um diferencial as peças. Como o material escolhido para o desenvolvimento deste artigo é considerado inusitado, delimitou-se que, para esta coleção, o público alvo será diferenciado, tendo gostos e opiniões próprias, personalidade e que gostem de inovações e que se preocupem com questões sustentáveis. Como visto, o material EPS é um poliestireno, uma resina que está incluída no grupo dos termoplásticos. Este é um material bastante problemático no mundo quando se pensa em reciclagem, sendo desvalorizado por ter menos interesse econômico. O EPS ocupa um grande volume, sendo um material com baixa densidade, elevando assim o custo de seu transporte, e diminuindo o interesse comercial. Portanto é necessário por parte do consumidor e fabricantes um posicionamento correto para o descarte deste.

Para auxiliar no desenvolvimento das peças, primeiramente foram delimitados requisitos para o projeto, alguns obrigatórios e outros desejáveis, listados abaixo:

a) As peças que serão desenvolvidas na coleção precisam ser leves e com boa ergonomia, ou seja, devem trazer conforto e segurança para o consumidor. Para este requisito, o EPS enquadra-se neste perfil, sendo um material pouco denso.

b) Outro requisito para este projeto, são peças de fácil usabilidade, sem complicação na colocação e/ou retirada das mesmas.

c) Por questões sustentáveis, para desenvolver as peças, os materiais utilizados devem, futuramente, gerar menos resíduos. Todos os materiais que serão utilizados na coleção, tais como o metal e o EPS, podem ser utilizados novamente, sendo reciclados para a fabricação de novas peças.

d) Todas as peças desenvolvidas terão uma base metálica para o apoio do resíduo de EPS, para este não ficar em contato direto com a pele do usuário.

e) As peças serão assimétricas, conceituais e únicas, pois o EPS é um material com aditivos de expansão e para efetuar uma reciclagem, será necessária uma modelagem específica, sem a obtenção de amostras iguais.

Após a delimitação dos requisitos fez-se necessária a realização de alguns testes para a verificação de como o EPS seria empregado nas peças. Para isso, foi efetuado um total de 4 ensaios, descritos abaixo. Para os testes, foram coletados resíduos de EPS de uso doméstico, por amigos, 
familiares e pelas autoras do artigo, nas cores branca, preta e verde. Também, alguns destes resíduos utilizados foram doados pelas Associações de Triagem da ASMAR e da ARSELE. Todos os resíduos foram higienizados antes da concretização dos testes. Para a delimitação de quais testes seriam realizados com o EPS, foi feita uma breve pesquisa na literatura e em meios eletrônicos.

Para a execução do primeiro teste (Figura 05), foi utilizada água quente sobre o EPS. Foram cortadas quatro amostras de EPS, com aproximadamente $2,5 \times 3 \mathrm{~cm}$ de tamanho, em diferentes cores e espessuras $(\approx 0,1 \mathrm{a} 0,4 \mathrm{~cm})$ e alocados em um recipiente cerâmico (Figura0 $5 \mathrm{~A}$ ). Primeiramente ferveu-se $200 \mathrm{ml}$ de água durante 10 minutos e verteu-se o líquido no recipiente com as amostras, conforme a Figura 05 B. Na Figura $05 \mathrm{C}$ visualiza-se as amostras logo após o preenchimento total com a água quente. Após 10 minutos, nenhuma alteração no formato das amostras foi percebida nos resíduos, conforme a Figura 05 D.
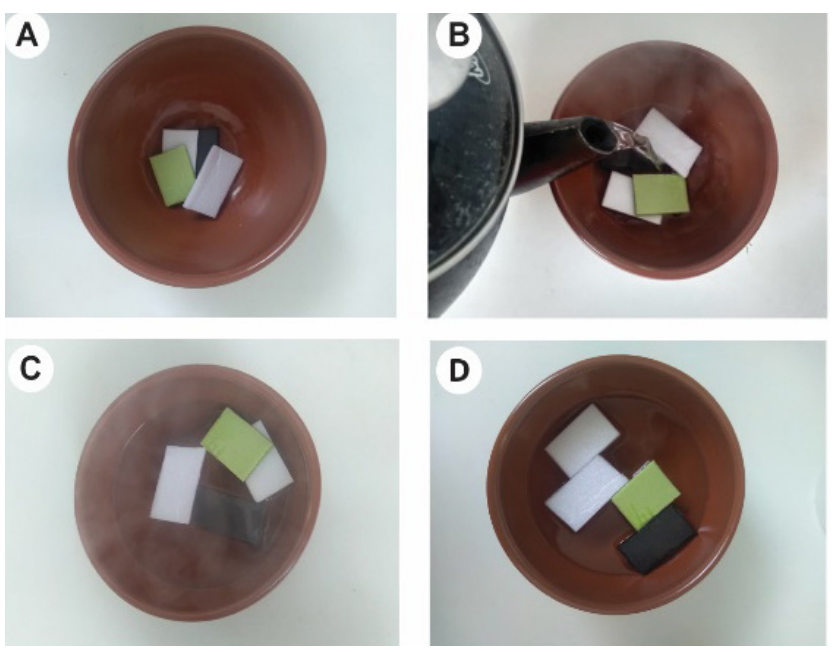

Figura 05 - Primeiro teste: (A) amostras de EPS, (B) água quente inserida nos resíduos, (C) primeiro minuto depois que a água foi colocada no recipiente e (D) resultado depois de 10 minutos Fonte: Autoras.

Para a realização do segundo teste (Figura 06) foram adicionadas as mesmas amostras de EPS do primeiro teste em um recipiente com cerca de $500 \mathrm{ml}$ de água fria, onde este foi aquecido lentamente (Figura 06 A). Após 5 minutos a água começa a ferver e percebe-se que o EPS começa a se curvar (Figura 06 B). A Figura $06 \mathrm{C}$ mostra que depois de 10 minutos com o fogo ainda ligado, as formas continuam com a mesma curvatura que na imagem anterior. As amostras foram retiradas da água e, ainda quentes, foi possível manuseá-las para verificar se ficariam quebradiças (Figura 06 D). Com estas amostras, notou-se que sua forma não voltou ao normal, ficando curvadas.
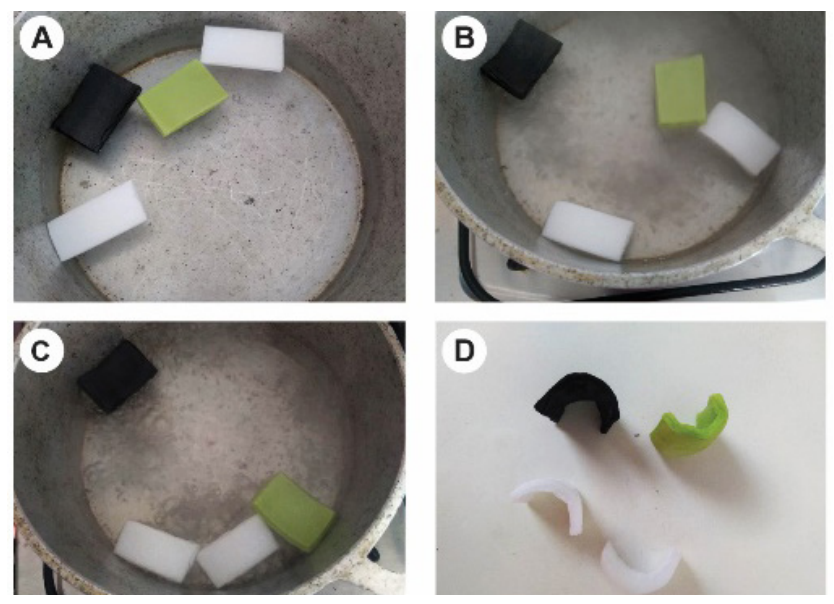

Figura 06 - Segundo teste: (A) amostras de EPS com a água ainda fria, (B) 5 minutos depois, (C) 10 minutos depois e (D) resultado do EPS

Fonte: Autoras.

Para a realização do terceiro teste, optou-se em utilizar o mesmo método da água quente, porém adicionando-se os resíduos na água já quente (Figura 07). Primeiramente foram cortados diferentes formatos de EPS, e em seguida ferveu-se $500 \mathrm{ml}$ de água durante 3 minutos. As amostras foram adicionadas na água quente conforme a Figura $07 \mathrm{~A}$. A Figura $07 \mathrm{~B}$ mostra que depois de 5 minutos com o fogo ligado as formas começam a se curvar, e visualiza-se que as formas triangulares são as mais curvadas (Figura 07 C). Após 10 minutos o fogo foi desligado e as amostras foram retiradas da água (Figura $07 \mathrm{D}$ ). $\mathrm{Na}$ Figura $07 \mathrm{E}$ pode-se notar na vista frontal as amostras que obtiveram maior curvatura. Já na Figura 07 F, a vista lateral das mesmas amostras. Notou-se que sua forma permaneceu no mesmo estado curvado, não voltando ao estado normal.
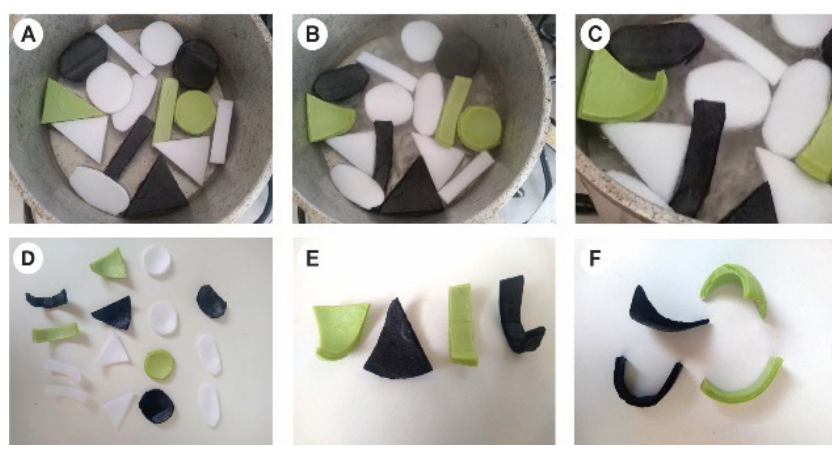

Figura 07 - Terceiro teste: (A) adição das amostras na água na quente, (B) 5 minutos depois as formas se curvando, (C) resultado da forma que mais se curvou, (D) retirada das amostras da água, (E) vista frontal das amostras que mais obtiveram resultado e (F) vista lateral das mesmas Fonte: Autoras.

Para o quarto teste (Figura 08), optou-se pela utilização de um método de reciclagem química com o uso de acetona pura como um meio solvente. Primeiramente as amostras de EPS foram cortadas (Figura $08 \mathrm{~A}$ ) em tamanhos iguais $(\approx 2,5 \mathrm{x}$ $3 \mathrm{~cm}$ ) e pesadas em uma balança de precisão obtendo cerca 
de 1,1 gramas cada. Na Figura 08 B observa-se o resíduo na cor preta sendo adicionado no líquido, já na Figura $08 \mathrm{C}$ o resíduo sendo retirado com a ajuda de uma espátula metálica. O mesmo processo foi realizado com EPS na cor verde (Figura $08 \mathrm{D}$ e E), e na cor branca (Figura 08 F). Observa-se que os resíduos, logo após terem a acetona adicionada, começam a sofrer alterações. A explicação para esse processo dá-se pelo fato de que a acetona enfraquece as interações entre os monômeros (estirenos), liberando todo ar até então preso entre as moléculas (SOUZA, 2014). Após todos os resíduos passarem pelo processo da acetona, foi possível moldá-los e acomodá-los em um recipiente metálico (Figura $08 \mathrm{G}$ ) que, em seguida, foi colocado ao ar livre por cerca de 24h, conforme a Figura $08 \mathrm{H}$. Na Figura 08 I e J visualizam-se as amostras após 24h, as quais obtiveram inúmeros formatos. Quando os resíduos são retirados da acetona, nota-se um odor forte, sendo que, após às $24 \mathrm{~h}$ ao ar livre, o solvente volatiza e o cheiro some por completo.

Após o quarto teste, as amostras resultantes foram pesadas para a verificação de volume. Em virtude dos diferentes formatos e tamanhos as amostras ficaram com 0,7 a 0,9 gramas aproximadamente. Com os testes realizados, considera-se que as amostras que utilizaram acetona obtiveram um melhor resultado de reciclagem.

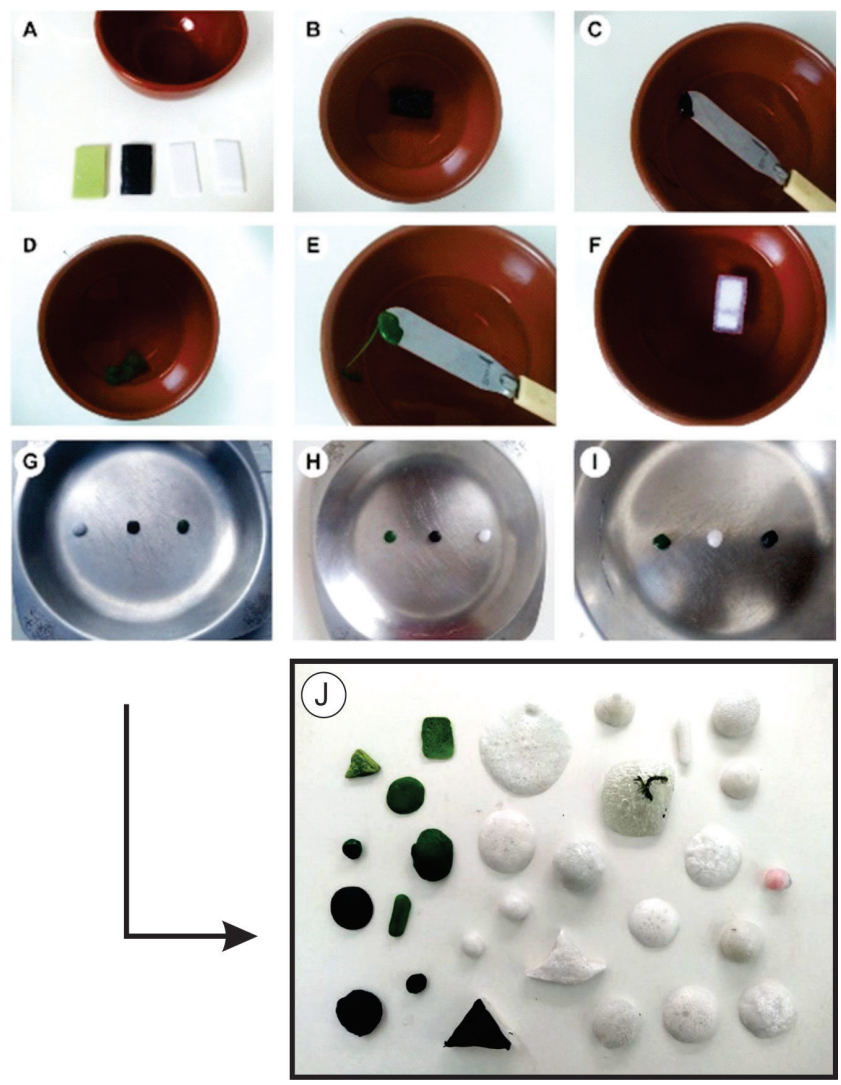

Figura 08 - Quarto teste: (A) amostras, (B) EPS preto na acetona, (C) EPS sendo retirado da acetona, (D) EPS verde, (E) amostra sendo retirada da acetona, (F) EPS branco, (G) algumas modelagem dos resíduos, (H) três resíduos ao ar livre, (I) e (J) resultado após 24h Fonte: Autoras.
Após os ensaios e experimentações realizados foi possível entender o material, para este ser aplicado nas futuras criações. Com isto, foram criadas três peças joalheiras, sendo elas um anel, um bracelete e um par de brincos (Figura 09).
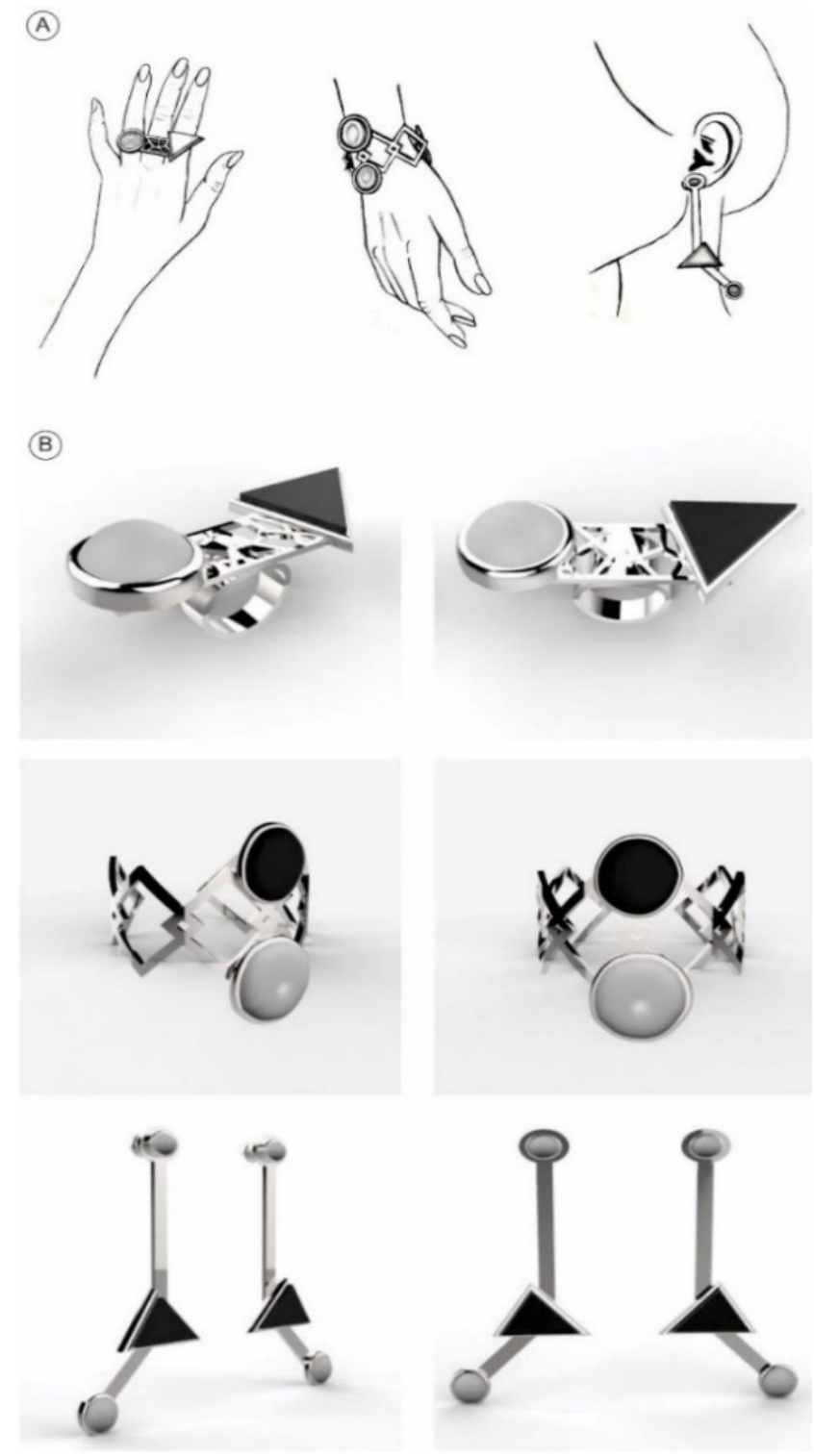

Figura 09-Joias com EPS: (A) criaçõese (B) modelagem via software do anel, bracelete e par de brincos Fonte: Autoras.

A temática seguida para o processo criativo das joias foi através de formas geométricas (Figura 09 A), as quais vinham de encontro ao formato resultante dos testes com a água quente e a acetona. Também para a criação, segundo os requisitos propostos, nas joias serão utilizadas caixas metálicas para acoplar o EPS, a fim de ter maior segurança e ergonomia. Na Figura 09 B é mostrado uma modelagem virtual via software Rhinoceros ${ }^{\circledR}$ das peças criadas, evidenciando as caixas metálicas com o material 
EPS na tonalidade branca e preta. Este software é utilizado para modelagem tridimensional, usualmente empregado em várias áreas do design de produtos e principalmente na de joalheria. Através desta modelagem é possível verificar detalhes da criação e, também, efetuar pequenos ajustes as peças para posterior fabricação. Para este artigo, foi delimitado que a peça do anel seria fabricada, por motivos de ser única e de dimensões reduzidas.

Para o processo de fabricação do anel, o material metálico utilizado junto com o EPS foi a prata 950 (Ag), considerada um material nobre e bastante utilizado na joalheria pelas suas propriedades (LEFTERI, 2014; LIMA, 2006). A prata possui um alto brilho, condutibilidade térmica, é maleável, dúctil e reciclável (LEFTERI, 2014). Segundo Lefteri (2014), o metal é considerado macio, de modo que para torná-lo manuseável é preciso ligá-lo ao cobre, onde $95 \%$ da liga é formada por prata e $5 \%$ de cobre. Todos os processos de fabricação que envolvem o desenvolvimento desta peça foram efetuados no Laboratório de Joalheria, da Universidade Federal de Santa Maria (UFSM).

Para o processo de fabricação da peça metálica do anel (Figura 10), primeiramente, utilizou-se o processo de usinagem CNC para a posterior fundição e acabamento da peça.
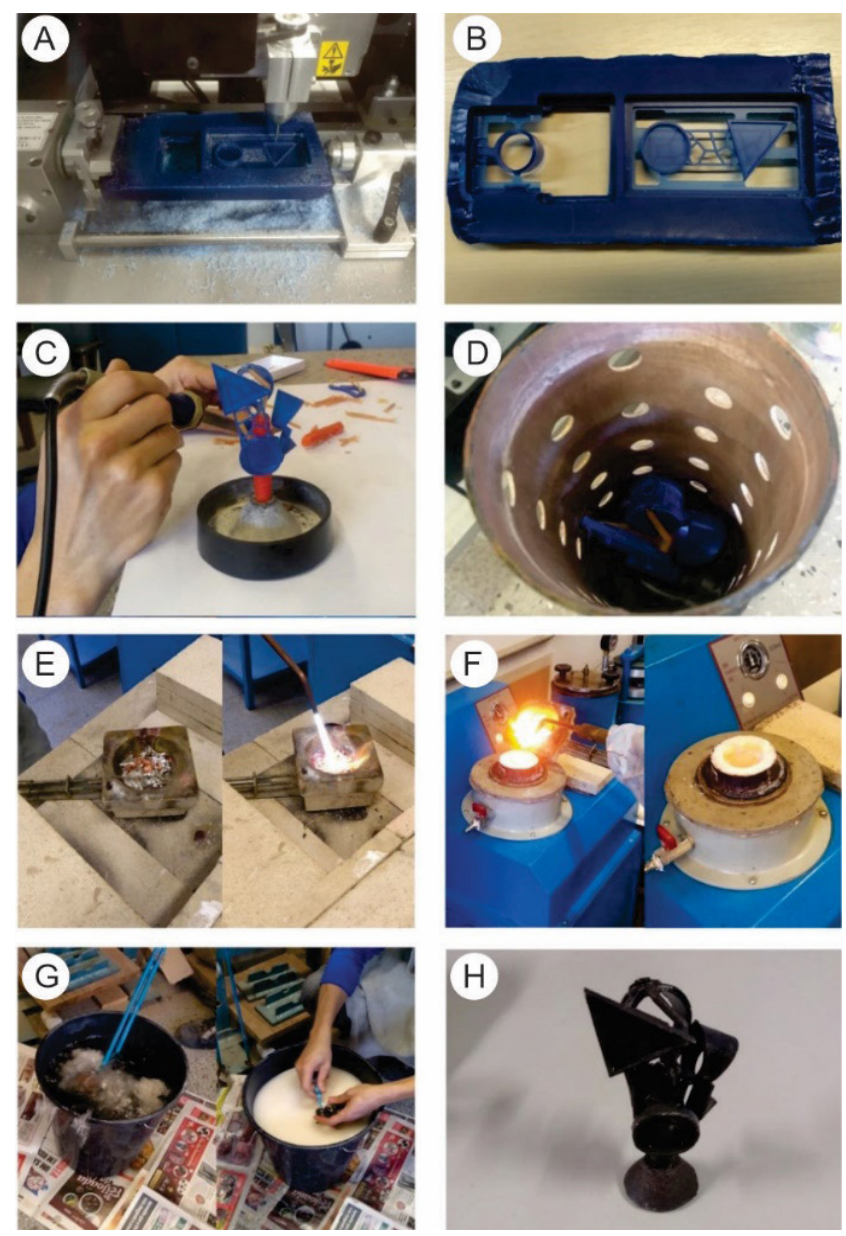
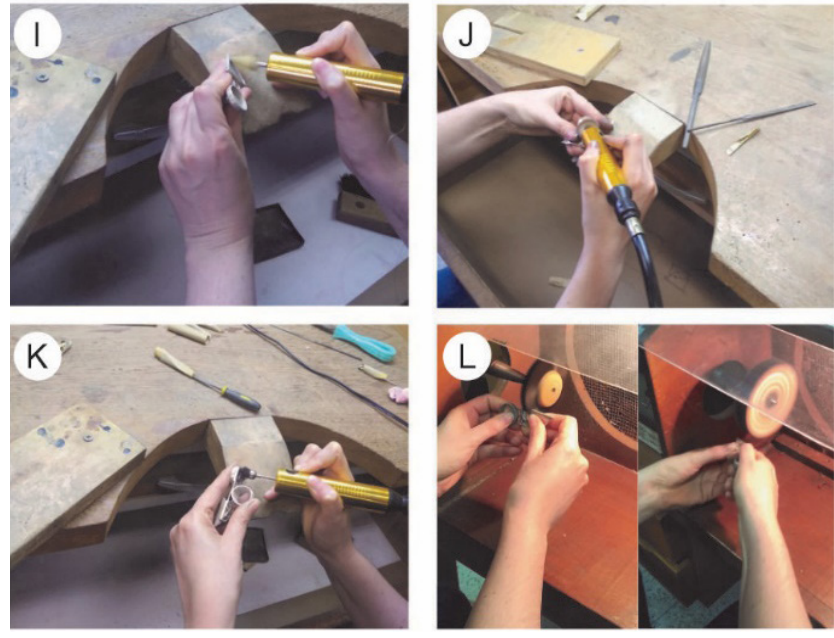

Figura 10 - Usinagem, preparação do molde de gesso e acabamento na peça já fundida em metal: (A) peça sendo usinada na cera, (B) peça pronta, (C) montagem da árvore de cera, (D) árvore alocada no tubo, (E)w fundição da prata com o cobre, (F) inserção do metal no molde de gesso, (G) desmanche do molde; (H) peça de prata; (I) e (J) processo de lixamento e (K) e (L) polimento da peça Fonte: Autoras.

Na Figura 10 A é mostrada a peça sendo usinada em cera. Já na Figura 10 B, a peça finalizada com os suportes de usinagem. Após a retirada e limpeza das peças foi possível montar uma espécie de "árvore" de cera, como mostra a Figura $10 \mathrm{C}$. Nesta, as partes usinadas são fixadas através de cabos de alimentação, os chamados "gitos", onde o metal irá passar. Depois de montada a árvore, esta é inserida em um tubo metálico para posterior vertimento da massa cerâmica, o gesso (Figura 10 D). Posteriormente, o tubo é inserido em uma câmara de vácuo para a retirada de possíveis bolhas. Depois de seco, o tubo com a massa cerâmica é inserido em um forno Mufla da marca Zezimaq ${ }^{\circledR}$ para a eliminação de água e da cera usinada. Este processo é chamado de deceragem. Após, os tubos passam por um processo de calcinação, para a retirada da umidade residual e para tornar o gesso mais resistente ao metal líquido que será vertido. Com o tubo de gesso aquecido, passou-se para o processo de vertimento do metal (Figura $10 \mathrm{E}$ ), onde o tubo aquecido foi retirado do forno e alocado em um equipamento a vácuo para aumentar a eficiência do preenchimento do metal (Figura 10 F). Após, o metal é vertido no tubo, completando assim a fundição e obtendo a árvore com as peças metálicas (Figura $10 \mathrm{H}$ ). Estas são cortadas com o auxílio de uma serra de corte. Em seguida foram colocadas em uma solução de água com ácido sulfúrico para limpá-las. Após isso, as peças foram limadas e lixadas (Figura 10 I e J), passando por um acabamento final de polimento (Figura $10 \mathrm{~K} \mathrm{e} \mathrm{L).} \mathrm{Com} \mathrm{a} \mathrm{peça} \mathrm{finalizada} \mathrm{pode-}$ -se prosseguir para o próximo passo, de análise de resultado e da validação da peça produzida. 


\section{RESULTADO E VALIDAÇÃO}

Após a etapa de materialização do anel com EPS são apresentados os resultados alcançados, tanto do material reciclado quanto da fabricação da peça metálica. Os resíduos de EPS foram aplicados na coleção das joias com intuito de valorizar o material e conscientizar sobre a possível reciclagem do mesmo. $O$ anel que compõe a coleção possui formas geométricas vazadas, o que torna a peça leve para combinar com o próprio material utilizado, o EPS. As caixas onde acoplam o EPS são bastante vistosas, para chamar atenção no material utilizado. Na Figura 11 podemos visualizar os resultados do anel produzido em prata 950 e EPS (Figura $11 \mathrm{~A}$ ) por meio de um ensaio fotográfico. Para a validação da peça foram feitos registros com usuários (Figura 11 B e C), podendo assim, ser observado questões referentes ao tamanho, peso e ergonomia da peça.
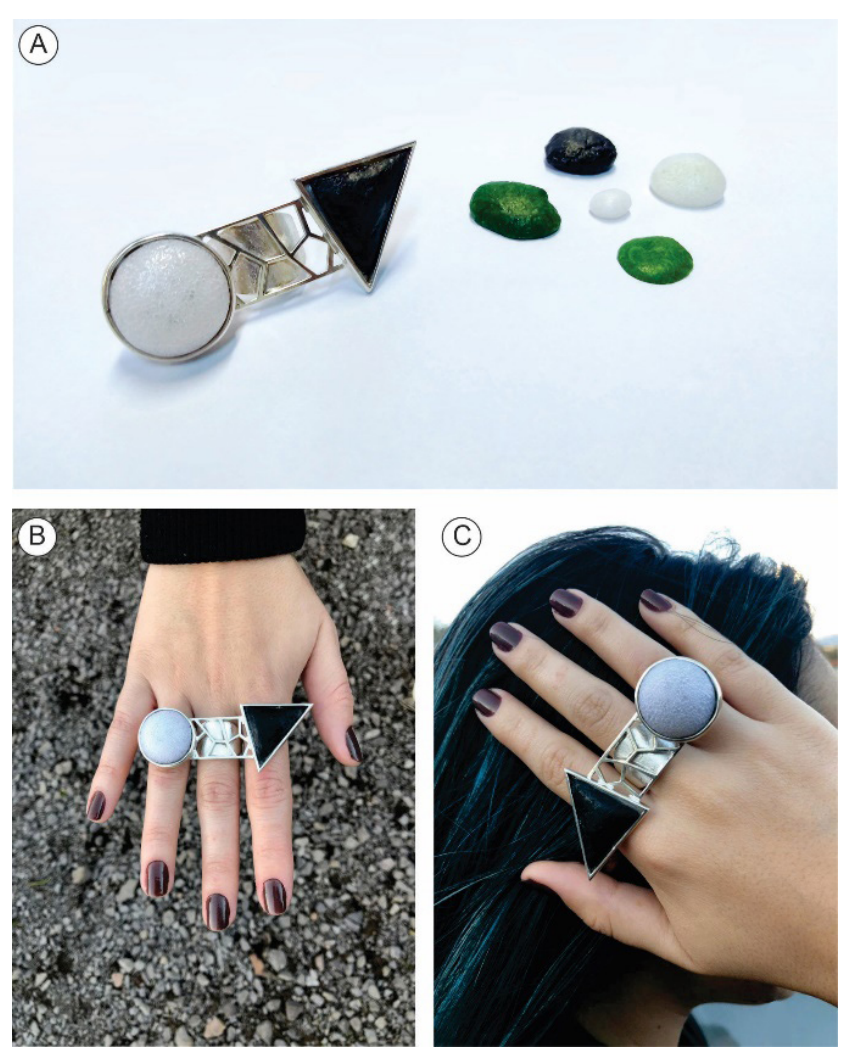

Figura 11 - Anel finalizado: (A) resultado da peça com o EPS reciclado; (B) e (C) ensaio fotográfico do anel sendo utilizado

Fonte: Autoras.

\section{CONSIDERAÇÕES FINAIS}

Este artigo teve como objetivo mostrar um estudo relacionado ao descarte de um material problemático para o meio ambiente, o EPS, mostrando o valor que esse resíduo pode proporcionar através da joalheria. As visitas feitas nas Associações foram importantes para esse trabalho, para que fosse possível conhecer o real problema do descarte dos materiais oriundos do lixo. Outro fator importante foi o mapeamento dos contêineres na cidade de Santa Maria, onde se pôde mostrar a má distribuição e a falta de estrutura para receber os RSU e dar a destinação correta a eles.

Os testes realizados com o EPS foram satisfatórios e possibilitaram um entendimento maior sobre o material para sua aplicação. A realização do teste com acetona mostrou que é possível reciclar o material transformando-o por completo em um novo produto, sem a ocorrência de odor na peça. Todavia, esse teste mostrou que cada vez que o material passa por um novo processo, ele vai ficando mais resistente à acetona. Sugere-se que para estudos futuros, sejam feitos testes para averiguar esta resistência. Já a prata, pode e deve ser reciclada inúmeras vezes, proporcionando uma variedade de criações. Também é preciso considerar a dificuldade encontrada na moldagem artesanal desejada do EPS, para depois passar para a peça de prata. O material não foi vertido na peça pronta em virtude de possíveis reações do metal com a acetona. Por esta razão a peça em EPS foi moldada separadamente, antes da modelagem em software para posterior usinagem. Por essa dificuldade, cada peça produzida será única. Por outro lado, analisou-se que com uma bandeja de EPS, podem ser feitas 8 amostras para esta coleção, proporcionando uma variedade de formatos e tornando possível a reciclagem deste material.

Mesmo com estas dificuldades e aprendizados, os objetivos propostos por este artigo foram atingidos, pois foi possível desenvolver uma coleção de joias aliada à sustentabilidade. O designer tem como uma das suas funções criar e desenvolver produtos e serviços que venham a auxiliar projetos sociais e que tragam uma melhora para problemas globais. Com isto, acredita-se que com pequenas atitudes, mesmo não sendo um projeto de design que envolva a reciclagem em maior escala, este trabalho apresenta uma possibilidade de recuperação e valorização de um material sem nenhum interesse comercial. Além disso, determinados pontos podem ser propostos para melhorar o cenário dos RSU, como o uso de informações mais claras pelos órgãos responsáveis pela coleta nas cidades. Por exemplo, os próprios contêineres poderiam possuir informações do descarte correto aos consumidores. Com uma maior conscientização da população, a separação do lixo seria mais adequada, ajudando, assim, as associações e centros de triagem além de, consequentemente, gerar mais renda às famílias vinculadas a este sustento.

\section{AGRADECIMENTOS}

Às Associações ASMAR e ARSELE. 


\section{REFERÊNCIAS}

ABRELPE. Panorama dos resíduos sólidos no Brasil. 2017. Disponível em: <http://abrelpe.org.br/pdfs/panorama/panorama_abrelpe_2017.pdf $>$ Acesso em: 1 ago. 2018.

ASHBY, M; JOHSON, K. Materiais e design: arte e ciência da seleção de materiais no design de produto. Rio de Janeiro: Elsevier, 2011.

AZAPAGIC, A.; EMSLEY, A.; HAMERTON, L. Polymers, the Environment and Sustainable Development. Chichester, UK: John Wiley \& Sons, 2003.

BARELLI, B. G. P. Design para a sustentabilidade: modelo de cadeia produtiva do bambu laminado colado (BLC) e seus produtos. 2009. 131 f. Dissertação (Mestrado - Programa de Pós-Graduação em Design) - Universidade Estadual Paulista "Júlio de Mesquita Filho", Bauru, 2009.

BRASIL. LEI No 12.305 DE 2 DE AGOSTO DE 2010. Institui a Política Nacional de Resíduos Sólidos; altera a Lei no 9.605, de 12 de fevereiro de 1998; e dá outras providências. Diário Oficial [da] República Federativa do Brasil. Brasília, DF, 2 ago. 2010.

CADORE, E. M. Joalheria contemporânea e sustentabilidade: recuperação de metais e lapidação de vidros a partir de resíduos. 2015. 118 f. Trabalho de Conclusão de Curso - Universidade Federal do Rio Grande do Sul, Porto Alegre, 2015.

CARVALHO, T. C. M. B.; XAVIER, L. H. Gestão de resíduos eletroeletrônicos. Rio de janeiro: Elsevier, 2014. IPEA - INSTITUTO DE PESQUISA ECONÔMICA APLICADA. Diagnóstico dos resíduos sólidos urbanos. Brasília: IPEA, 2012. Disponível em: <http://www. ipea.gov.br/agencia/images/stories/PDFs/relatoriopesquisa/121009_relatorio_residuos_solidos_urbanos.pdf $>$. Acesso em: 1 ago. 2018.

JUNIOR, A. B. C. Gerenciamento de resíduos sólidos urbanos com ênfase na proteção de corpos d'água: preservação, geração e tratamento de lixiviados de aterros sanitários. Rio de Janeiro: ABES, 2006.

JURAS, I. A. G. M. Resíduos. 2012. Disponível em: <https://www2.camara.leg.br/atividade-legislativa/estudos-e-notas-tecnicas/publicacoes-da-consultoria-legislativa/areas-da-conle/tema14/2012_1658.pdf>. Acesso em: 4 out. 2018.

LEFTERI, C. Materials for design. London: Laurence King Publishing, 2014.

LIMA, M. A. Introdução aos materiais e processos para designers. Rio de Janeiro: Editora Ciência Moderna Ltda., 2006.
MANCINI, S. D.; ZANIN, M. Resíduos plásticos e reciclagem: aspectos gerais e tecnologia. São Paulo: Ed.UFSCar, 2004.

MANZINI, E. Design para a inovação social e sustentabilidade: Comunidades criativas, organizações colaborativas e novas redes projetuais. Rio de Janeiro: E-papers, 2008.

MATGE, P. R. Santa Maria terá de esperar até setembro de $\mathbf{2 0 1 8}$ para coleta seletiva por contêineres. 2018a. Disponível em: <https://diariosm.com.br/not\%C3\%ADcias/geral/santa-maria-ter\%C3\%A1-de-esperar-at\%C3\%A9-setembro-de-2018-para-coleta-seletiva-por-cont\%C3\%AAineres-1.2006971>. Acesso em: 20 abr. 2018a.

MATGE, P.R. Santa Maria tem 121 focos de descarte irregular. 2018b. Disponível em: <https://diariosm. com.br/not\%C3\%ADcias/geral/santa-maria-tem-121-focos-de-descarte-irregular-1.204679?I=. Acesso em: 20 abr. 2018b.

MATGE, P. R. Vida útil do aterro municipal de santa maria é de 10 anos. 2018c. Disponível em: <https:// diariosm.com.br/not\%C3\%ADcias/geral/vida-\%C3\%BAtil-do-aterro-municipal-de-santa-maria-\%C3\%A9-de-10-anos-1.2046818>. Acesso em: 20 abr. 2018c

PALOMBINI, F. Design de equipamento híbrido para o reprocessamento de resíduos poliméricos: aglutinador e moinho de facas. 2015. 256 f. Trabalho de Conclusão de Curso - Universidade Federal do Rio Grande do Sul, Porto Alegre, 2015.

PALOMBINI, F. L.; CIDADE, M. K.; JACQUES DE JACQUES, J. How sustainable is organic packaging? A design method for recyclability assessment via a social perspective: A case study of Porto Alegre city (Brazil). Journal of Cleaner Production, v. 14, p. 2593-2605, 4 november. 2016. DOI: 10.1016/j.jclepro.2016.11.016

PARLAMENTO EUROPEU. Resíduos de plástico e reciclagem. 2018. Disponível em: <http://www.europarl. europa.eu/news/pt/headlines/society/20181212STO21610/residuos-de-plastico-e-reciclagem-na-ue-factos-e-numeros>. Acesso em: 4 out. 2018.

PELTIER, F.; SAPORTA, H. Design sustentável: caminhos virtuosos. São Paulo: Editora Senac São Paulo, 2009.

PENNA, E. Bélgica tem o melhor sistema de reciclagem de lixo da Europa. 2017. Disponível em:<https://www.brasileiraspelomundo.com/belgica-tem-o-melhor-sistema-de-reciclagem-de-lixo-da-europa-110855721>. Acesso em: 6 set. 2018. 
PEREIRA, A. O. K.; HORN, L. F. D. R. Relações de consumo: Meio ambiente. Caxias do Sul, RS: Educs, 2009. PLASTICS EUROPE. Plastics - The Facts 2013: An analysis of European latest plastics production, demand and waste data. Bruxelas: Plastics Europe, 2013. Disponível em: <http://www.plasticseurope.org/cust/documentrequest.aspx?DocID=59108>.

PLASTIVIDA - INSTITUTO SÓCIO-AMBIENTAL DOS PLÁSTICOS. Polímeros. Disponível em:<http://www. plastivida.org.br/index.php?lang=pt>. Acesso em: 24 mar. 2018.

SCHERER, A.; VIEIRA, R. O lixo que sai caro. 2015. Disponível em: < https://exame.abril.com.br/revista-exame/o-lixo-que-sai-caro/>. Acesso em: 7 out. 2018. SEBRAE. O que são resíduos (e o que fazer com eles). 2017. Disponível em: <http://www.sebrae.com. br/sites/PortalSebrae/artigos/o-que-sao-residuos-e-o-que-fazer-com-eles,ca5a438af1c92410VgnVCM100000b272010aRCRD?origem=segmento\&codSegmento=13>. Acesso em: 21 abr. 2018.

SOUZA, L. F. Derreter isopor na acetona é possível? Disponível em:<https://sites.unipampa.edu.br/ pibid2014/files/2017/08/reacoes-quimicas-com-isopor-lucas-fagundes-de-souza.pdf $>$. Acesso em: 13 abr. 2019.

VEZZOLI, C.; MANZINI, E. O desenvolvimento de produtos sustentáveis. São Paulo: Editora da Universidade de São Paulo, 2008.

WALKER, S. Sustainable by design: explorations in theory and pratice. London: Routledge, 2006.

\section{AUTORES}

ORCID: https://orcid.org/0000-0001-6563-0562

SUELLEN DO NASCIMENTO DE SOUZA MORENO, DESIGNER | Universidade Federal de Santa Maria - UFSM | Desenho Industrial | Santa Maria-RS, Brasil | Correspondência para: Av. Roraima, 1000, prédio 40, sala 1136 | Email: suellennsm42@gmail.com.

ORCID: https://orcid.org/0000-0001-5893-383X

MARIANA KUHL CIDADE, DRA. | Universidade Federal de Santa Maria - UFSM | Departamento de Desenho Industrial | Santa Maria-RS, Brasil | Correspondência para: Av. Roraima, 1000, prédio 40, sala 1136 | Email: mariana.cidade@ufsm.br

\section{COMO CITAR ESTE ARTIGO}

MORENO, Suellen do Nascimento de Souza; CIDADE, Mariana Kuhl. Sustentabilidade e Joalheria: Reciclagem de Eps para Aplicação em Joias. MIX Sustentável, [S.I.], v. 5, n. 4, p. xx-xx, nov. 2019. ISSN 24473073. Disponível em:<http://www.nexos.ufsc.br/index.php/ mixsustentavel>. Acesso em: dia mês. ano. doi:https:// doi.org/10.29183/2447-3073.MIX2019.v5.n4.xX-XX.

DATA DE ENVIO: 25/08/2019

DATA DE ACEITE: $27 / 09 / 2019$ 